\title{
Management of Oesophageal Foreign Bodies
}

\author{
N. Subrahmanyam ${ }^{1}$, T. Rajendra Prasad $^{2,}$ K. Santhaiah ${ }^{3}$ \\ ${ }^{I}$ Associate Professor of ENT, Guntur Medical College, Guntur, India, 9848242280. \\ ${ }^{2}$ Associate Professor of ENT, Siddhartha Medical College, Vijayawada, India, 9848134024. \\ ${ }^{3}$ Professor of ENT, Guntur Medical College, Guntur, India, 9848134031.
}

\begin{abstract}
Objective: This study of Esophageal foreign bodies presenting at casualty, E.N.T. and Pediatrics Departments Govt. General Hospital, Guntur from 2012 to 2015 was conducted to know the epidemiology, clinical features, diagnosis, different techniques of foreign body removal and complications during their removal and management.

Material And Methods: A total of 50 patients with a clear history of foreign body ingestion with chief complaint of dysphagia and /or odynophagia were admitted and treated in Govt. General Hospital, Guntur during the period from 2012 to 2015. There were 8 adult males, 6 adult females and 36 children. The main symptoms were difficulty and pain during swallowing, drooling of saliva, vague sensation of foreign body, and pain neck. All patients were subjected to thorough physical examination and radiological investigations In cases of radiolucent foreign bodies with history of strong suspicion, flexible oesophagoscopy was undertaken to confirm or otherwise instead of contrast study.

Results: Rigid oesophagoscopy under general anesthesia was performed to remove FB successfully in all cases expect one case of impacted denture in esophagus, which required cervical oesophagotomy after failed removal through oesophagoscopy.
\end{abstract}

Conclusion: Rigid oesophagoscopy under general anesthesia is still the golden standard for removal of FB'S in oesophagus.

Keywords: FB (foreign body), oesophagoscopy, oesophagotomy.

\section{Introduction}

Foreign body ingestion with impaction is commonly encountered in the extremes of age, psychiatry patients, edentulous patients and rarely patients with benign/malignant strictures. Most of the FBs in children were coins followed by button batteries and plastic toy accessories. In elderly group dentures, mutton pieces, chicken pieces and fish bones are commonly seen foreign bodies. The most common site of impaction is cricopharyngeal sphincter. Preexisting benign or malignant strictures sometimes present as acute onset dysphagia without any history of foreign body ingestion, precipitated by normal food intake.

\section{Material And Methods}

From 2012 through 2015, fifty patients with esophageal foreign bodies attending the departments of ENT, Pediatrics and Casualty at GGH, Guntur were treated on an emergency basis. There were 8 adult male (16\%), 6 adult females (12\%) and 36 children (72\%) ranging in age from infant to 60 years (Table -1). Majority of the patients presented with the chief complaint of acute onset of dysphagia and odynophagia. Only one patient had neck swelling after a failed attempt to remove the denture from upper end of esophagus. None of our adult patients had a history of psychiatric illness or alcoholism. Plain $x$-ray neck Lateral view for soft tissues was taken for all the patients and AP and Lateral views including oropharynx, neck, chest and abdomen were taken whenever necessary and foreign body removal was done under general anesthesia with rigid oesophagoscope. Every patient was subjected to check x-ray before giving general aneasthesia especially if there is a time gap of more than 24 hours from the time of admission to intervention to exclude spontaneous expulsion to the exterior or migration of the foreign body to lower G I tract. In cases of radiolucent foreign bodies with history of strong suspicion, flexible oesophagoscopy was undertaken to confirm or otherwise instead of contrast study.

\section{Results}

Age distribution was shown in table-1. In our study coin was the commonest FB and it is seen almost exclusively in children below eleven years. Types of foreign bodies seen in our study coin (42\%) is the most common and the rest follow in the descending order like chicken bone, fish bone, button batteries, meat bolus, eraser, dentures, safety pin and plastic whistle. In our study Cricopharynx is the most frequent site of foreign 
body impaction in food passage (80\%) followed by lower and mid oesophagus. All foreign bodies were successfully removed by rigid oesophagoscopy except one which required oesophagotomy.

Table-1 Age Distribution ( $\mathrm{n}=50)$

\begin{tabular}{|c|c|c|}
\hline Age in years & No. of cases & Percentages \\
\hline Infants to 10 Years & 36 & $72 \%$ \\
\hline 11 to 20 Years & 3 & $6 \%$ \\
\hline 21 to 30 years & 4 & $8 \%$ \\
\hline 31 to 40 Years & 3 & $6 \%$ \\
\hline 41 to 50 Years & 2 & $4 \%$ \\
\hline 51 to 60 Years & 2 & $4 \%$ \\
\hline
\end{tabular}

Table-2 nature of foreign body

\begin{tabular}{|c|c|c|}
\hline Type of FB & No. of cases & Percentage \\
\hline Coin & 21 & $42 \%$ \\
\hline Chicken Bone & 13 & $26 \%$ \\
\hline Fish Bone & 4 & $8 \%$ \\
\hline Meat Bolus & 3 & $6 \%$ \\
\hline Button batteries & 3 & $6 \%$ \\
\hline Erasure & 2 & $4 \%$ \\
\hline Denture & 2 & $2 \%$ \\
\hline Safety pin & 1 & $2 \%$ \\
\hline Plastic whistle & 1 & \\
\hline
\end{tabular}

Table-3 Site of FB Lodgement

\begin{tabular}{|c|c|c|}
\hline Site of FB Lodgement & Number of cases & Percentage \\
\hline Cricopharynx & 40 & $80 \%$ \\
\hline Mid oesophagus & 4 & $8 \%$ \\
\hline Lower oesophagus & 6 & $12 \%$ \\
\hline
\end{tabular}

\section{Discussion}

Foreign bodies in oesophagus must be removed by oesophagoscopy under general anesthesia and before removal of it the surgeon must have knowledge of the nature, size, and site of foreign body and if possible a replica should be examined. Coin is the most common foreign body in children and is also stuck in and around cricopharynx most of the time. As the pharyngeal constrictors are stronger than esophageal smooth muscle, a coin can reach the level of the cricopharynx but it is unable to go further down in the oesophagus in most of the circumstances. The radiological examination must be repeated before oesophagocopy is done because the coin may have moved into the stomach, if there has been delay between time of admission and removal. The cold light oesophagoscope was used to remove the coin with alligator forceps.

Two precautions must be taken while attempting to remove the sharp foreign bodies like fish bone, chicken bone, dentures, safety pin etc,

1. The anaesthetist must take care not to pass the endotracheal tube blindly because it may accidentally go in to the oesophagus and cause perforation of the oesophagus.

2. Surgeon must resist the temptation to extract the foreign body quickly without noting the position of its sharp edge.

Meat and soft foreign bodies are extracted piecemeal. Cancer of oesophagus may present as a case of an impacted food bolus. Hence after endoscopic removal of foreign body/food bolus it is important to reenter to check that there is no underlying intrinsic oesophageal lesion. In cases with dentures as foreign bodies radiographs should be carefully studied with regard to the hooks and sharp points on the denture. Then the denture can be removed by manipulating either the hooks into the lumen of the oesophagoscope or by breaking the denture in situ and then extracting. Some foreign bodies require removal by external approach. One of our patients presented with denture impaction throat and after unsuccessful removal in first attempt, required oesophagotomy to deliver the denture. One case of safety pin oesophagus with pointed end embedded in mucosa of esophagus was dislodged gently and brought into oesophagoscope and removed. 


\section{Conclusion}

The tremendous advancements in endoscopic techniques during the last century coupled with safe anesthetic techniques have made removal of foreign bodies from the esophagus a relatively safe procedure. Oesophagoscopy is a reliable method in the treatment of oesophageal FB impaction, alternative methods like surgical treatment is unavoidable in cases of irretrievable FB or oesophageal perforation. Modern denture plates made of acrylic, being radiolucent may cause delay in the diagnosis and treatment. At the same time optical forceps with magnification on CCTV monitor making identification, manipulation and extraction of the FB's relatively easier.

\section{References}

[1]. Tekinbaş C, Erol M. Video-mediastinoscopy: for extracting upper esophageal foreign bodies. Ann Thorac Surg 2007; 83: 22392240

[2]. Little DC, Shah SR, Peter SD, et al. Esophageal foreign bodies in the pediatric population: our irst 500 cases. J Pediatr Surg 2006; 41:914-918.

[3]. Naidoo RR, Reddi AA. Chronic retained foreign bodies in the esophagus. Ann Thorac Surg 2004; 77: 2218-2220. 6. Athanassiadi K, Gerazounis M, Metaxas E,

[4]. Silverberg M, Tillotson R. Esophageal foreign body mistaken for impacted button battery. Pediatric Emergency Care 2006; 22: 262265.

[5]. Abdullah BJ, Teong LK, Mahadevan J, et al. Dental Prosthesis ingested and impacted in the esophagus and orolaryngopharynx. J Otolaryngol.1998; 27:190-4.

[6]. De Ruiter MH, Van Damme P A, Drenth JP. Serious Complications following removal after ingestion of a Partial denture. Ned Tijdschr Tandheelkd. 2008;115[5]:267-70.

[7]. Yeoh NT. Impacted dentures in the oesophagus.Med J Malaysia.1982;37: 344-48.

[8]. Brunello DL, Mandikos MN.A denture swallowed: Case report, Aust Dent J 1995;40

[9]. (6):349-51.

[10]. De Ruiter MH. Van Damme PA,Drenth JP. Serious complications following removal of an Ingested partial denture. Ned Tijdschr Geneeskd 2007; 151 (3):194-7.

[11]. Nwafo DC, Anyanwu CH, Egbue MO. Impacted esophageal foreign bodies of dental origin. Ann Otol Rhinol Laryngol 1980;89:129-31.

[12]. Nwaorgu OG, Onakoya PA, Sogebi OA, Kokong DD, Dosumu OO. Esophageal impacted Dentures. J Natl Med Assoc 2004; 96(10):1350-3

[13]. Samarasam I, Chandran S, Shukla V, Mathew G.A missing denture`s midadventure! Dis Esophagus 2006; 19 53-55.

[14]. Lai AT,Chow TL, Lee DT,Kwok SP. Risk factors predicting the development of complications after foreign body ingestion. Br J Surg 2003; 90: 1531-35. 